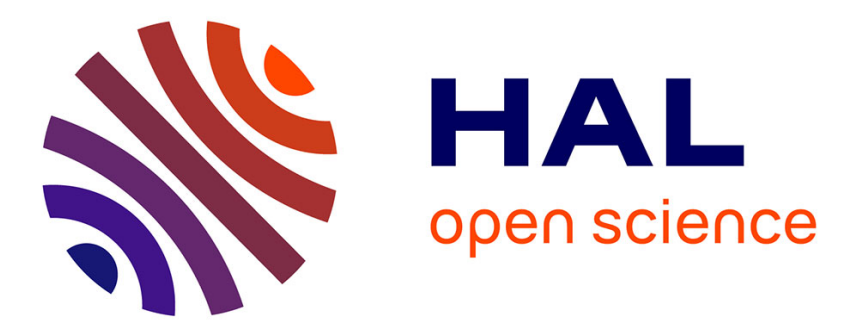

\title{
Alignment of practices for an efficient management of Systems Engineering processes during the development of systems of systems
}

Rui Xue, Claude Baron, Philippe Esteban, Li Zheng

\section{- To cite this version:}

Rui Xue, Claude Baron, Philippe Esteban, Li Zheng. Alignment of practices for an efficient management of Systems Engineering processes during the development of systems of systems. IEEE Third World Conference on Complex Systems, Dec 2015, Marrakech Morocco. hal-01284543

HAL Id: hal-01284543

https://hal.science/hal-01284543

Submitted on 7 Mar 2016

HAL is a multi-disciplinary open access archive for the deposit and dissemination of scientific research documents, whether they are published or not. The documents may come from teaching and research institutions in France or abroad, or from public or private research centers.
L'archive ouverte pluridisciplinaire HAL, est destinée au dépôt et à la diffusion de documents scientifiques de niveau recherche, publiés ou non, émanant des établissements d'enseignement et de recherche français ou étrangers, des laboratoires publics ou privés. 


\section{Alignment of practices for an efficient management of Systems Engineering processes during the development of systems of systems}

\author{
Rui XUE ${ }^{1,2}$, Claude Baron ${ }^{1,2}$ \\ ${ }^{1}$ CNRS, LAAS, Toulouse, France \\ ${ }^{2}$ Univ. de Toulouse, INSA, LAAS, Toulouse, France
}

\author{
Philippe Esteban ${ }^{1,3}$,Li Zheng ${ }^{1,2}$ \\ ${ }^{3}$ Univ de Toulouse, UPS, LAAS, Toulouse, France \\ \{rxue,claude.baron,philippe.esteban, li.zheng\}@laas.fr
}

\begin{abstract}
Nowadays, because of the increasing complexity of systems and projects, more and more people focus on the systems of systems. At the same time, Systems Engineering and Project Management are considered as two independent activities during the development of systems of systems, but many inconsistencies appear between Systems Engineering and Project Management teams during engineering projects although their relationships is needed to be integrated as they get involved in large scale systems of systems. For the most part, these inconsistencies are due to a not close enough coordination and sometimes a lack of communication. As a result, there is a great need for international companies to understand the standards or guides from both domains to better integrate them and enhance their chances of success. Although numerous Systems Engineering and Project Management standards or guides have been published to help people get better organized and improve the quality of products or services, a lot of their projects still fail due to the poor integration of both domains. At the same time, the number of small and medium enterprises has quickly increased because the social division of labor is becoming more and more meticulous with the rapid development of the science and technology. The ability for small and medium enterprises to analyze and apply the Systems Engineering and Project Management standards or guides is not the same as for international companies, due to their limited resources. So the aim of this paper is to select two references from the most frequently used standards or guides in Systems Engineering and Project Management domains, the ISO/IEC 15288 and the PMBoK, and to illustrate how to help the systems engineers and project managers to compare and align the references from both domains quickly and effectively.
\end{abstract}

Keywords- systems engineering; project management; standards or guides; alignment

\section{INTRODUCTION}

At present, with the increasing complexity of projects, it is obvious that Systems Engineering (SE) and Project Management (PM) teams need to intensify their relationships as they get involved in large scale projects or systems[1]. As a result, there is a need for systems engineers and project managers to understand the standards or guides from both domains to better integrate them and enhance their chances of success. Although numerous SE and PM standards or guides have been published to help people get better organized and improve the quality of products or services, a lot of projects still failed. The Standish Group pointed out that only $16.2 \%$ of software projects are completed successfully, on time and on budget. However not all of successful projects achieve features and functions originally proposed. It is also worth noting that only $9 \%$ of projects in big companies were successful while $31.1 \%$ of projects will be cancelled before they ever get completed [2]! According to the report drawn up by INCOSE $\mathrm{UK}$, the effective use of systems engineering can save not only 10 to $20 \%$ of the project budget, but can also prevent half of all failures [3]. It is well-known that some failures are due to inconsistencies and a lack of consultation between the different teams involved in the same project from Systems Engineering and Project Management [4]. The technical team will follow the project from a technical perspective, making use of engineering knowledge in an attempt to solve the technical problems, whereas the managerial team will follow the project globally by using key performance indicators to evaluate the success of the project. So in this paper, we consider the Systems Engineering and Project Management as two essential activities of the project. This paper aims to select one reference amongst the most commonly used ones in SE and in PM and to compare them, in order to assess whether a bridge could be built in the framework of systems of systems between the two references so as to provide a view shared by systems engineers and project managers enabling them to carry out the project successfully.

\section{INTEGRATING SE AND PM: A RECENT ISSUE!}

In a highly competitive environment, companies have to improve their performance and practices to successfully implement their projects. The current issues deal with how to simplify and speed up processes to better coordinate, control and manage these projects. Thus, there is a need not only to integrate systems engineering processes and project management processes, but also to help engineers and managers supervise and conduct the project by implementing methods and support tools allowing them to make decisions jointly. So far, international organizations have devised many SE and PM standards, guides or references (e.g., ANSI/EIA 632, IEEE 1220, INCOSE HandBook and SEBoK for SE, or PMBoK and ISO 21500 for PM). However not a single standard or guide contemplates an advanced cooperation between SE and PM, despite the fact that engineers and manager have to cooperate closely throughout the whole project development. So one has to compare and analyze the

China Scholarship Council (CSC) 
differences and similarities between SE and PM standards or guides and to supplement them during project implementation.

In order to improve the performance of SE and PM, research has recently been carried out. In 2011, INCOSE (the International Council on Systems Engineering) and PMI (Project Management Institute) recognized the importance of integrating SE with PM and agreed to tackle the question to help organizations reduce risks and improve returns on investment [5]. Based on this consensus, the MIT took out a survey and pointed out the need to overcome the barriers between systems engineers and project managers. They suggested four methods to enhance cooperation based on the analysis of several cases: using standards from both domains, formalizing the definition of integration, developing integrated engineering program assessments and sharing responsibility for risk management, quality, lifecycle planning and external suppliers [5]. In May 2012, a guide named "the guide to lean enablers for managing engineering programs" was published by the joint MIT-PMI-INCOSE community of practice on lean in program management after a one year research on the integration of operations research, systems engineering and project management. It is suggested to be used by the managers and engineers to improve their performances during the whole project. The authors collected and synthesized data to provide the best guidance on how to implement the project more successfully [6].

This paper addresses the first suggestion made by MIT: to have standards cooperate. To do so, we reviewed the standards and guides from both domains [7], compared them [7][8], and conducted a survey on a panel of industrialists to identify the most commonly used standards and guides: in SE, the ISO/IEC 15288 standard is the one most often used while in PM, the $\mathrm{PMBoK}$ is also the most internationally followed guide. In the next section both references are considered.

\section{INTRODUCTION TO ISO/IEC 15288 STANDARD AND PMBOK GUIDE}

With the increasing globalization of markets, international standards have become critical to the trading project, ensuring the product and services meet internationally recognized levels of performance and safety. So companies are encouraged to use international standards or guides. A great deal of standards and guides are used by companies as reference [9]. They can be subdivided into three categories: Product standards or guides, Process standards or guides and Project management standards or guides. Among them are many popular standards, such as ISO 9000 about quality management, ISO 14000 about environmental management and ISO 31000 about risk management. The PMI only focuses on drawing up the guides or standards related to management.

\section{A. ISO 15288}

The ISO/IEC 15288 is a Systems Engineering standard covering processes and life cycle stages. [11]. Many other standards or SE references, such as INCOSE SE Handbook and SEBoK, are based on the ISO/IEC 15288.

This standard defines a set of processes that are applied to the development of product, systems or services and the associated terminology. It defines the systems life cycles as six stages: conception, development, production, utilization, support and retirement. It can be applied concurrently, iteratively and recursively to a system and its elements. The systems considered in this international standard are man-made, created and utilized to provide products and/or services for the benefit of users and other stakeholders [11].

ISO/IEC 15288 standard is broken down into 3 levels processes (Figure 1). The first level features four process groups; there are 25 processes in total in the four process groups at the second level. Each process is presented in terms of purpose, outcomes and activities at the third level.

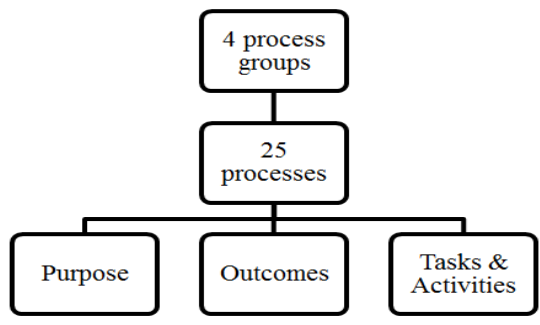

Figure 1. Structure of ISO/IEC 15288

\section{B. $P M B o K$}

The PMBoK is a guide about project management; it provides the widely recognized standard and guidelines for project managers to deal with the management of the project effectively. Not only does it contain the standard that describes processes, input and output of the processes, but also guides about the tools and methods to be used as a resource in managing projects while considering the overall approach and methodology to be followed [12]. The PMBoK can be used before starting a project or at any steps to formalize it without overlooking some key parameters.

The PMBoK is also broken down into 3 levels (Figure 2); there exists 10 Knowledge Areas at the first level. A Knowledge Area represents a complete set of concepts and activities that make up a professional field, project management field, or area of specialization. To these 10 areas correspond 5 process groups at the second level. These have clear dependencies and interact with one another.

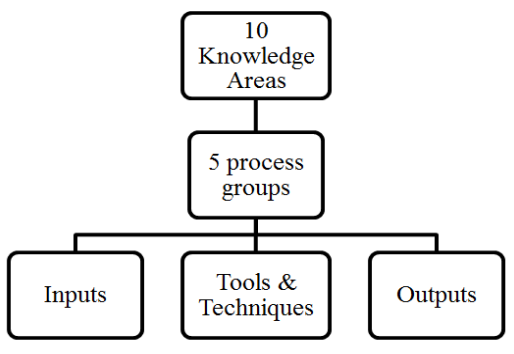

Figure 2. Structure of PMBoK 


\section{COMPARING ISO/IEC 15288 AND PMBOK ON THEIR STRUCTURE}

This section compares ISO/IEC 15288 and PMBoK with respect to their structure, first considering the first level decomposition then the second one.

\section{A. Comparison on the First Level of Decomposition}

After analyzing the processes of the 10 knowledge areas in $\mathrm{PMBoK}$, we will find that almost in each Knowledge Area (KA) have two similar processes: the planning process and the controlling process, there are nine Knowledge Areas (KAs) that have the planning processes and eight KAs have the processes in the monitoring and controlling process groups. It is as shown in Figure 3 and Figure 4.

\begin{tabular}{|c|c|}
\hline \multicolumn{2}{|c|}{ Planning process groups } \\
\hline Plan Scope Management & Plan Quality \\
\hline Plan Schedule & \\
\hline Management & $\begin{array}{c}\text { Plan Human Resources } \\
\text { Management }\end{array}$ \\
\hline $\begin{array}{c}\text { Plan Communications } \\
\text { Management }\end{array}$ & $\begin{array}{c}\text { Plan Procurement } \\
\text { Management }\end{array}$ \\
\hline Plan Cost Management & Plan Stakeholder \\
\hline Plan Risk Management & Manageme \\
\hline
\end{tabular}

Figure 3. Relationship between planning process groups and 10 Knowledge Areas that all the process in the Figure 3 of PMBoK can be founded in the project planning process of ISO/IEC 15288. The processes of monitoring and controlling process group in the Figure 4 can be founded in the Project Assessment and Control Process of ISO/IEC 15288.

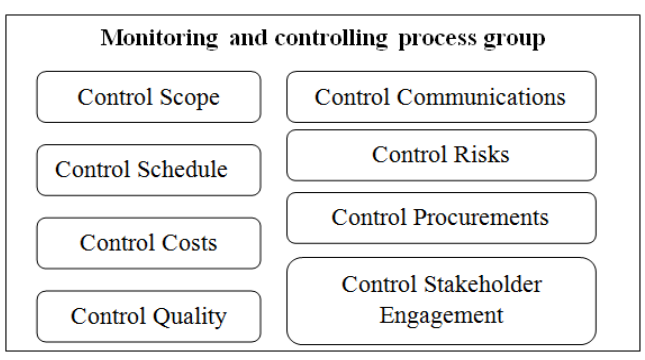

Figure 4. Relationship between the monitoring and controlling process group and 10 Knowledge Areas

After aligning the two process groups of PMBoK to the two processes of ISO/IEC 15288, we compare all the processes of ISO/IEC 15288 to the 10 Knowledge Areas of PMBoK. This comparison is based on ISO/IEC 15288; so, Figure 5 highlights those parts of the PMBoK covered or not covered by said standard. If a knowledge area in the longer dashed rectangle, it means that this knowledge area is only partially covered by ISO/IEC 15288. If it is in the solid rectangle, it means that the whole knowledge area can be found in said standard.

After analyze parts of the two process groups, we found

ISO/IEC 15288

PMBoK

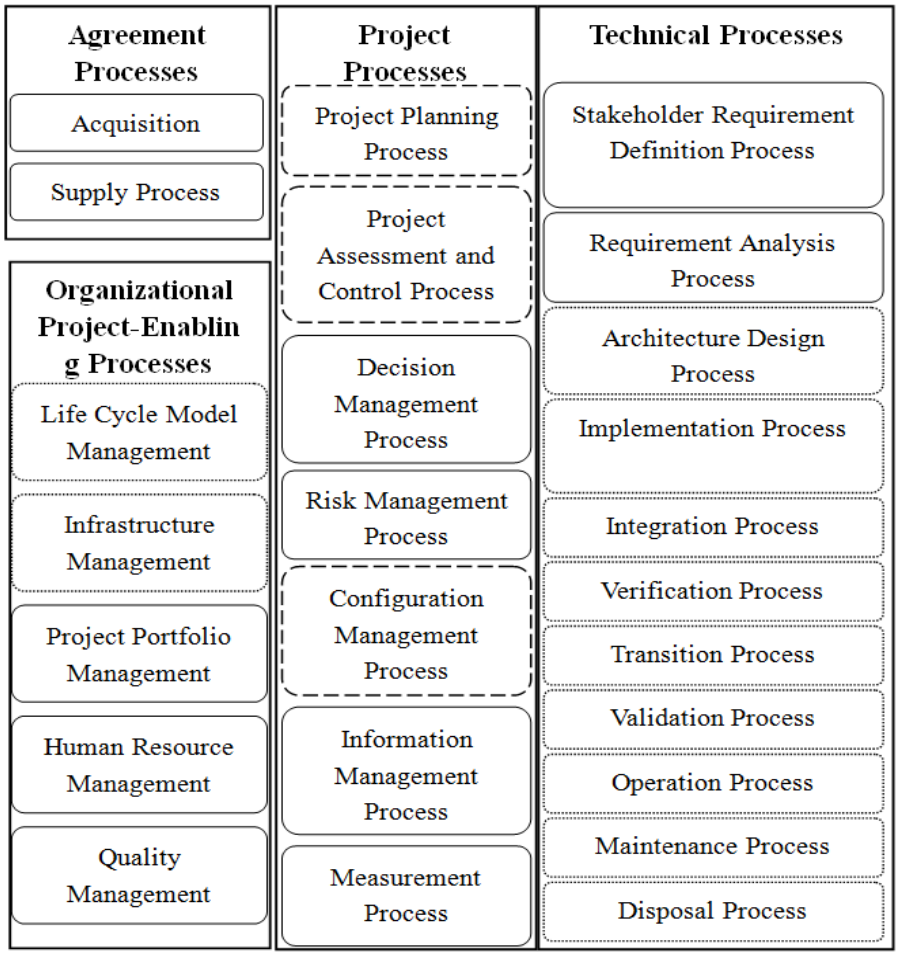

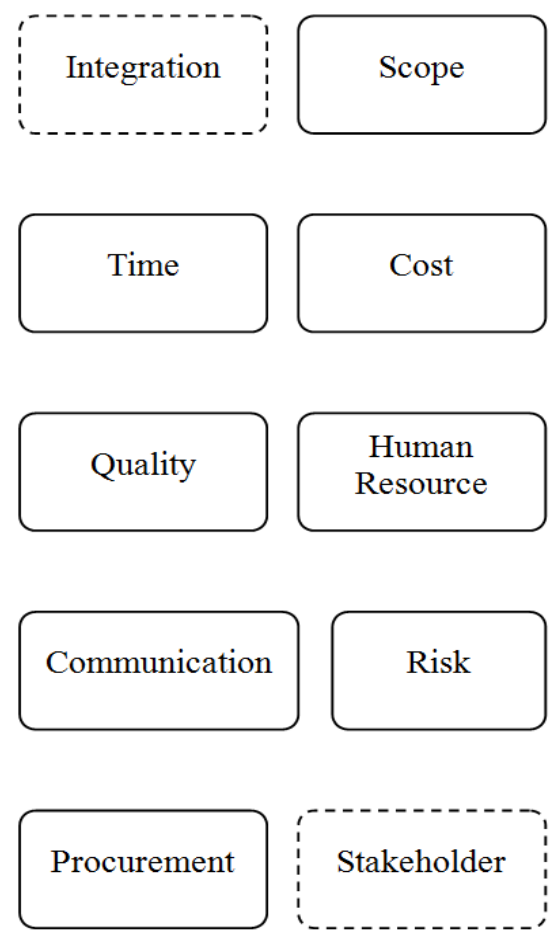

Figure 5. Comparison between ISO/IEC 15288 and PMBoK at the first level 
Based on the analysis above, we give some detailed alignment of both references; the result is shown as the table I.

TABLE I. SOME DETAILED ALIGNMENT OF PROCESSES OF THE TWO REFERENCES

\begin{tabular}{|c|c|}
\hline ISO/IEC 15288 & PMBoK \\
\hline $\begin{array}{ll}\text { 1. } & \text { Project Planning Process-Define the project. } \\
\text { 2. } & \text { Stakeholder Requirements Definition Process } \\
\text { 3. } & \text { Architectural Design Process } \\
\text { 4. } & \text { Validation Process } \\
\text { 5. } & \text { Project Assessment and Control Process }\end{array}$ & \begin{tabular}{ll} 
& \multicolumn{1}{c}{ Project Scope Management } \\
1. & Plan Scope Management \\
2. & Collect Requirement \\
3. & Define Scope \\
4. & Create WBS \\
5. & Validate Scope \\
6. & Control Scope \\
\end{tabular} \\
\hline $\begin{array}{ll}\text { 1. } & \text { Project Planning Process- } \\
\text { 2. } & \text { Project Assessment and Control Process } \\
\text { 3. } & \text { Project Assessment and Control Process }\end{array}$ & $\begin{array}{l}\text { Project Quality Management } \\
\text { 1. Plan Quality Management } \\
\text { 2. Perform Quality Assurance } \\
\text { 3. } \\
\end{array}$ \\
\hline $\begin{array}{l}\text { 1. Project Planning Process } \\
\text { 2. Project Assessment and Control Process }\end{array}$ & $\begin{array}{l}\text { Project Communications Management } \\
\text { 1. Plan Communications Management } \\
\text { 2. Manage Communications } \\
\text { 3. Control Communications } \\
\end{array}$ \\
\hline $\begin{array}{l}\text { 1. Project Planning Process } \\
\text { 2. Project Assessment and Control Process }\end{array}$ & $\begin{array}{l}\text { Project Procurement Management } \\
\text { 1. Plan Procurement Management } \\
\text { 2. Conduct Procurements } \\
\text { 3. Control Procurements } \\
\text { 4. Close Procurements } \\
\end{array}$ \\
\hline
\end{tabular}

\section{B. Comparison on the second level of decomposition}

Let us now consider the relationships between the tasks and activities of ISO/IEC 15288 and the 5 process groups of the PMBoK. We analyze all processes of the ISO/IEC 15288, we extract and classify the verbs that are been used to describe the tasks and activities of the processes. A distinct classifications can be found, they can be classified into five groups as shown in the left column of the table II. It is worth noting that the five verb groups exactly correspond to the names of the five process groups of PMBoK. This corresponding relationship between the two references is shown as in the table II.

TABLE II. RELATIONSHIP BETWEEN ISO/IEC 15288 AND THE PMBOK

\begin{tabular}{|l|l|}
\hline \multicolumn{1}{|c|}{ ISO/IEC 15288: Tasks \& activities } & $\begin{array}{c}\text { PMBoK: } 5 \text { process } \\
\text { groups }\end{array}$ \\
\hline $\begin{array}{l}\text { Prepare, Initiate, Identify, Establish, Define, } \\
\text { Elicit }\end{array}$ & Initiating \\
\hline Advertise, Develop, Plan, Manage & Planning \\
\hline $\begin{array}{l}\text { Execute, Evaluate, Acquire, Activate, } \\
\text { Analyse }\end{array}$ & Executing \\
\hline $\begin{array}{l}\text { Monitor, Deliver, Assess, Provide, Control, } \\
\text { Treat }\end{array}$ & $\begin{array}{l}\text { Monitoring and } \\
\text { Controlling }\end{array}$ \\
\hline $\begin{array}{l}\text { Accept, Close, Improve, Maintain, Perform, } \\
\text { Support, Finalize }\end{array}$ & Closing \\
\hline
\end{tabular}

Figure 6 shows one example about the alignment of activities and tasks of ISO/IEC 15288 and processes of PMBoK.

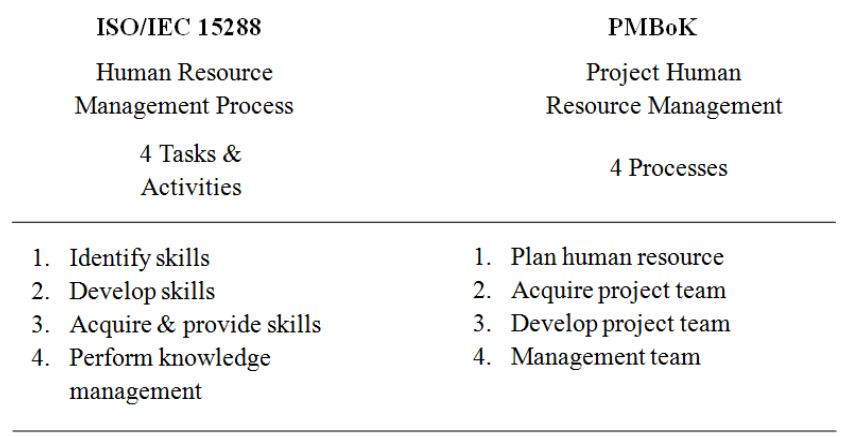

Figure 6. Process relationship between ISO 15288 and PMBoK

\section{Conclusion on the comparison of the ISO/IEC 15288 and PMBoK structures}

As the organizations of both references have already been presented and compared, levels of decomposition can be highlighted (see Figure 1 and Figure 2). Hence, general structures are compatible and this is the first similarity in both references. With respect to these figures, both references are broken down into three levels. However, these levels do not refer to the same thing, but a linear match between levels cannot be achieved at the same degree of decomposition. Nonetheless, by going deeper into each level, another more sophisticated match can be found. This is shown below in Figure 7. 


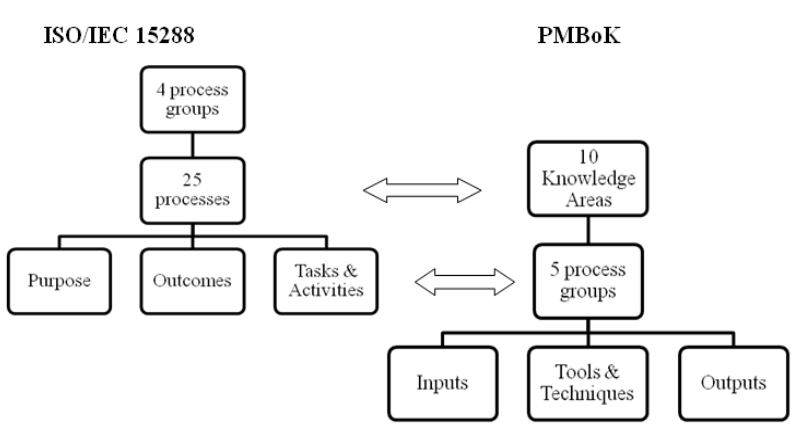

Figure 7. Match between the three levels of both references

\section{COMPARING ISO/IEC 15288 AND PMBOK ON THEIR CONTENT}

After comparing both organizations it is worthwhile having a look at the contents of both references

\section{A. Focus on different systems in both references}

After analyzing the focus of each system in both references, it becomes apparent that the two references focus on a different system. Indeed, the PMBoK's system is a project whereas ISO/IEC 15288's system is a product or a service. This point occurs in each knowledge area and in each sub-process.

For example, "Risk Management Process" in ISO/IEC 15288 deals with a product or service as shown in the following definition: "The Risk Management process is a continuous process for systematically addressing risk throughout the life cycle of a system product or service". Likewise, "Project Risk Management" in the PMBoK deals with a project as shown in the following definition: "Project Risk Management includes the processes of conducting risk management planning, identification, analysis, response planning, and controlling risk on a project".

Nevertheless, approaches, processes and steps are still the same. For example, every tasks and activities of the subprocess "Risk Management Process" (ISO/IEC 15288) matches every process of the knowledge area "Project Risk Management" as shown in the Table III.

TABLE III. FOCUS ON DIFFERENT SYSTEMS IN ISO/IEC 15288 AND PMBOK

\begin{tabular}{|c|c|}
\hline $\begin{array}{c}\text { Risk Management Process } \\
\text { (ISO/IEC 15288) }\end{array}$ & $\begin{array}{c}\text { Project Risk Management } \\
(\mathrm{PMBoK})\end{array}$ \\
\hline Tasks and Activities: & 5 processes: \\
\hline $\begin{array}{ll}\text { 1. } & \text { Plan risk } \\
\text { management }\end{array}$ & 1. Plan risk management \\
\hline $\begin{array}{l}\text { 2. Manage the risk } \\
\text { profile }\end{array}$ & 2. Identify risks \\
\hline 3. Analyse risks & $\begin{array}{l}\text { 3. Perform qualitative risk } \\
\text { analysis } \\
\text { 4. Perform quantitative risk } \\
\text { analysis }\end{array}$ \\
\hline 4. Treat risks & 5.Plan risk responses \\
\hline
\end{tabular}
5. Monitor risks
6.Control risks
6. Evaluate the risk management process

\section{B. Chronologically versus concurrently}

How to execute the processes is an important point if they can be implemented simultaneously or chronologically.

For the PMBoK, the 10 knowledge areas can be executed concurrently. Indeed, each knowledge area is an important project management field, and information about cost or time must always be available. All the knowledge areas will not begin and end at the same time but they are all independent. Conversely, the five processes must be executed one after the other (see Figure 8).
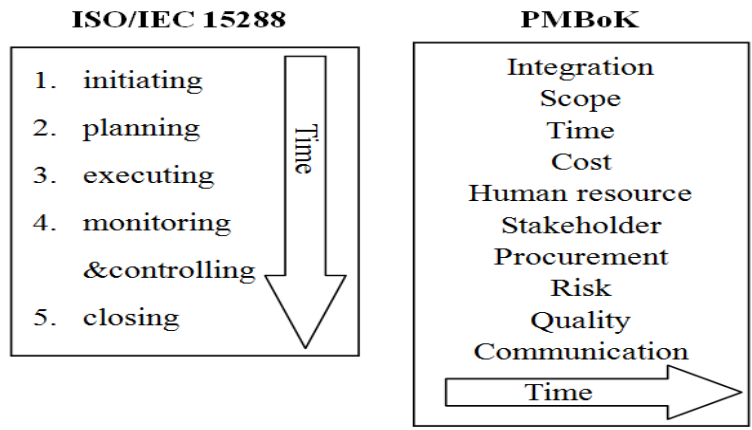

Figure 8. Major time considerations for ISO/IEC 15288 and PMBoK

For ISO/IEC 15288, the four process groups: "Agreement processes", "Technical processes", "Project processes" and "Organizational-project-enabling processes" can be executed concurrently. For sub-processes, some of them can run simultaneously while the others must be executed in a chronological order. For example, the two sub-processes "Acquisition Process" and "Supply Process" (pertaining to the "Agreement Processes") can run simultaneously (see Figure 9). However, almost all sub-processes which belong to the "Technical processes" must be executed one after the other. Finally, all "Tasks and Activities" in each sub-processes have to be executed in a chronological order.

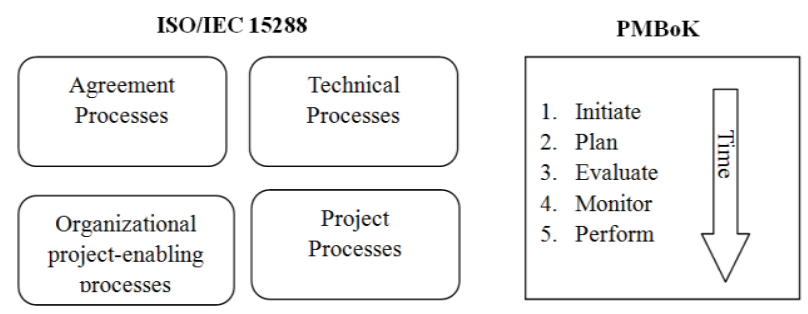

Figure 9. Some time considerations for ISO/IEC 15288

\section{Conclusion on the comparison of the ISO/IEC 15288 and PMBoK content}

The first general remark that can be made is that the degree of explanations differs in both references. The PMBoK is more detailed than ISO/IEC 15288. This can be easily verified by the 
number of pages. ISO/IEC 15288 is 84 pages long whereas $\mathrm{PMBoK}$ is 616 pages long. Moreover, the manner in which both documents are decomposed also accounts for these differences. On the one hand, in ISO/IEC 15288, there are just chapters for the 4 main categories of processes and one small part for each subprocess; on the other hand, in PMBoK, one chapter is devoted to each knowledge area and a small portion in each chapter is devoted to each process.

Secondly, it has been stated that in the decomposition of the 5 processes of PMBoK, there are some introductions about the tools and methods corresponding to the processes. It is really useful to know those tools or methods allowing the processes to be implemented effectively. However, the ISO/IEC 15288 standard does not mention the tools and methods that can be used during the implementation of the processes. Thirdly, one has to check whether words convey the same meaning in both references. Indeed, after reviewing the words used in both references, it appears that there are no real differences on the technical side; for example, the word "specification" or "risk" has the same meaning in both references. The only thing worth noticing is that the word "system" has a different meaning. Indeed, ISO/IEC 15288 focuses on technical systems whereas PMBoK deals with the "system" as projects. So this may account for the communication issue observed between stakeholders.

\section{CONCLUSION}

To develop the systems of systems quickly and effectively, it is better to know the references from the Systems Engineering and Project Management domains since they are two initial and critical elements of the systems of systems during their developments. How to better integrate them during the development for the systems engineers and project manager is a great challenge. In this paper, we considered the SE and PM as two important aspects of the development of systems of systems, and then the comprehensive study of the PMBoK and ISO/IEC 15288 has been conducted. Firstly, we introduced the two references briefly. Then, we compared them to highlight differences and similarities at different levels. We first compared them based on the general structures of both references, we analyzed ISO/IEC 15288 and PMBoK in terms of the processes and activities, and we also analyzed those parts of the reference covered by one or the other, in this part, we give some detail example of the similarities and differences. In the second part, we analyzed both contents to study their points of view. It was concluded that the type of systems on which the ISO/IEC 15288 reference focuses is a product or service, whereas the PMBoK focuses on a project. ISO/IEC 15288 focuses essentially on technical aspects and only a few concepts of project are treated. Conversely, PMBoK focuses only on the project aspect even if there are some same processes or activities. Then, each reference standard features its own specific parts but they are consistent, complementary and follow the same approach. When implementing the project management processes of ISO/IEC 15288, the tools or methods from PMBoK can be used as reference. These two references can also be employed differently. We can use the technical processes from $\mathrm{m}$ ISO/IEC 15288 standard to complete the PMBoK, when the technical process is needed during implementation of the project, we use ISO /IEC 15288 standard as reference, then we use the Project Management processes of the PMBoK

In order to complete the ultimate goal of integrating methods and tools from SE and PM during the development of systems of systems, one may align both references to facilitate the management of the technical project. However, how to mix these references remains an interesting area to explore.

\section{REFERENCES}

[1] N. Clemens, N., Systems Engineering (SE) \& Project Management [on line]http://www.incose.org/chesapek/docs/cy2004/presentations_04/syst ems\%20engineering\%20and\%20project\%20management.pdf

[2] The Standish Group: "The Standish Group Report", 2014.

[3] INCOSEUK: "Why do Systems Engineering? Manage Complexity. Reduce your Risk", 2009.

[4] L. Weingart, and A. J. Karen Manage, Intra-Team Conflict Through Collaboration. The Blackwell Handbook of Principles of Organizational Behavior, 2003.

[5] E. Conforto, M. Rossi, E. Rebentisch, J. Oehmen, M. Pacenza, "Survey Report: Improving Integration of Program Management and Systems Engineering". MIT Consortium for Engineering Program Excellence, 2013.

[6] J. Oehmen, B. W. Oppenheim, D. Secor, E. Norman et al. The Guide to Lean Enablers for Man-aging Engineering Programs. Joint MIT-PMIINCOSE Community of Practice on Lean in Program Management, 2012.

[7] R. Xue, C. Baron, P. Esteban, D. Esteve, and M. Malbert, "Towards the success of design projects by the alignment of processes in collaborative engineering", Proceedings of Joint Conference on Mechanical, Design Engineering \& Advanced Manufacturing. Toulouse, France, 18th-20th, June 2014.

[8] R. Xue, C. Baron, and P. Esteban, "How compatible Systems Engineering and Project Management standards are considering the way they manage Systems Engineering processes". 15e Congrès des Doctorants EDSYS (École Doctorale Systèmes) 22th-23th May 2014.

[9] ISO: What is a standard. [On line]: http://www.iso.org/iso/home/standards.html

[10] J.N. Martin, "Evolution of EIA 632 from an Interim Standard to a Full Standard", INCOSE 1998 Symposium, 1998.

[11] ISO/IEC. ISO/IEC/IEEE Systems and Software Eng. - System Life Cycle Processes. IEEE, 2008.

[12] PMI A Guide to the Project Management Body of Knowledge: PMBOK V5. PMI, 2013. 